\title{
Transmembrane potential changes and ventricular fibrillation during repetitive myocardial ischaemia in the $\operatorname{dog}^{1}$
}

\author{
D. C. RUSSELL, H. J. SMITH, AND M. F. OLIVER \\ From the Departments of Cardiology and Medicine, Royal Infirmary, Edinburgh
}

SUMMARY Electrophysiological changes occurring soon after experimental coronary occlusion have been examined in 13 dogs by combined recording of epicardial action potential, endocardial-epicardial conduction time, and epicardial ST segment elevation during successive 5-minute occlusions of the left anterior descending coronary artery. After initial coronary occlusion, action potential duration shortened from $182 \pm 9 \mathrm{~ms}$ to $113 \pm 9 \mathrm{~ms}$ at 2 minutes and conduction time was prolonged from $24 \pm 1 \mathrm{~ms}$ to $71 \pm 17 \mathrm{~ms}$ associated with progressive ST segment elevation. These changes were followed by the appearance of potentials of 'slow response' type morphology, alternans of action potential duration and amplitude, alternans of epicardial and endocardial ST segment elevation, and intermittent conduction block. Ventricular fibrillation was preceded by action potential alternans in 95 per cent and by conduction block in 65 per cent of instances and occurred at a time of maximum conduction delay. These data strongly support the concept of re-entry in the pathogenesis of early ventricular fibrillation.

Changes in action potential duration and conduction time were significantly greater during the first occlusion compared with subsequent occlusion periods. There was no significant difference however between data taken from occlusions $2,3,4$, or 5 . This questions the validity of experimental studies of myocardial ischaemia based on comparisons of sequential coronary occlusions using the first as the control.

The high incidence of arrhythmias and sudden death occurring in the first 2 hours of ischaemia in man can be related to the early phase of malignant ventricular arrhythmias that occurs soon after coronary occlusion in experimental animals (Harris, 1950; Oliver, 1976). Understanding of the pathogenesis of such arrhythmias in experimental animals has been largely derived from in vitro measurement of electrophysiological variables (Cranefield et al., 1972; Wit et al., 1974) or from intracellular recordings in the isolated perfused heart (Kardesch et al., 1958; Downar et al., 1977b). Pronounced slowing of conduction and heterogeneity of refractoriness have been shown in the ischaemic myocardium consistent with the initiation of arrhythmias by reentrant excitation (Han, 1969; Cox et al., 1973; Scherlag et al., 1974; Russell and Oliver, 1978).

Little is known however of the relation between

${ }^{1}$ This work was supported by grants from the Medical Research Council and the British Heart Foundation.

Received for publication 8 November 1978 transmembrane potential changes and arrhythmias in acute ischaemia. Assessment of this relation is most relevant when examined in the in situ heart and is possible by using the floating microelectrode technique (Woodbury and Brady, 1956; Prinzmetal et al., 1962; Czarnecka et al., 1973). We have recently described a technique for combined intracellular and extracellular recordings of action potential in vivo during acute myocardial ischaemia suited to the assessment of arrhythmogenesis (Russell et al., 1977), and using this combined technique, we report in the present study (a) the relations between intracellular potential changes, endo-epicardial ST segment elevation, and the onset of ventricular fibrillation after coronary artery occlusion, and (b) the reproducibility of these measurements after successive brief coronary artery occlusions in the anaesthetised dog.

\section{Methods}

Thirteen mongrel dogs (weight 11 to $15 \mathrm{~kg}$ ) were 
anaesthetised with sodium pentobarbitone $(30 \mathrm{mg} /$ $\mathrm{kg}$ intravenously followed by a maintenance infusion of $3 \mathrm{mg} / \mathrm{kg}$ per h controlled by a Harvard infusion pump; additional supplements of $3 \mathrm{mg} / \mathrm{kg}$ were occasionally required). Sodium chloride 0.9 per cent was infused at $50 \mathrm{ml} / \mathrm{h}$ throughout the experiment through a jugular or femoral vein. After intubation with a cuffed endotracheal tube and controlled ventilation with room air, a lateral thoracotomy was performed through the fifth left intercostal space. The heart was suspended in a pericardial cradle and the left anterior descending coronary artery was dissected free 2 to $3 \mathrm{~cm}$ from its origin and above its major diagonal branches. Arterial pressure was measured through a femoral arterial cannula using a Statham P23Db strain gauge transducer and displayed on a Devices chart recorder.

Bipolar pacing electrodes were sutured to the left atrial appendage and the heart was paced at 175 beats/min. In 5 dogs, atrial pacing was combined with right vagal stimulation (5 to $10 \mathrm{~mA}$ constant current pulse of $4 \mathrm{~ms}$ duration at $25 \mathrm{~Hz}$ ).

Epicardial electrograms were recorded from 5 small disc electrodes (diameter $5 \mathrm{~mm}$ ) sutured with fine silk to the epicardium within the potentially ischaemic zone of myocardium served by the exposed coronary artery; the electrodes were placed at least $1 \mathrm{~cm}$ distant from the probable border of the potentially ischaemic zone and recordings were only obtained after loss of injury potential. A mean signal was derived from an electronic averaging box which also allowed monitoring of any individual lead if required. The endocardial electrogram was recorded within the centre of the potentially ischaemic zone with a plunge electrode of fine insulated copper wire (diameter $0.11 \mathrm{~mm}$ ) approximately subjacent to the site of epicardial intracellular potential recording.

The cardiac action potential was recorded using our previously reported modification of the floating electrode technique (Russell et al., 1977). Optimal recordings are obtained with thick-wall glass electrodes $(2.5 \mathrm{~mm}$ external diameter; $1 \mathrm{~mm}$ internal diameter) rather than conventional electrodes ( 1 or $2 \mathrm{~mm}$ external diameter). The electrodes were pulled vertically with a slow early phase and a rapid late phase, and then filled with $3 \mathrm{M} \mathrm{KCl}$ by boiling under reduced atmospheric pressure. Prepared in this way, an acceptable electrode with a short distal tip and an electrical resistance of 10-15 $\mathrm{M} \Omega$ was obtained. Two floating electrodes were suspended from micro-manipulators and positioned within $1 \mathrm{~mm}$ of each other in the centre of the potentially ischaemic area of myocardium. One electrode was impaled to secure an intracellular record, and the other was used as an extracellular indifferent electrode. In some experiments the tip of a fine insulated silver wire was used as the indifferent electrode. The cardiac action potential was recorded by amplifying the potential difference between the electrodes with a high-input impedance amplifier and displaying the output on a DM 63 Tektronic storage oscilloscope using indirect calibration. The signals together with the endocardial and epicardial electrograms were recorded on magnetic tape for subsequent analysis. Selected periods were recorded on paper at $100 \mathrm{~mm} / \mathrm{s}$. Sequential measurements of action potential duration (95\% repolarisation) were performed. Small variations in diastolic potential which might affect action potential duration determination were eliminated by time measurement from 95 per cent depolarisation to 95 per cent repolarisation. Endocardial-epicardial conduction time, defined as the time from onset of the $R$ wave on the endocardial electrogram to the onset of epicardial activation on the intracellular recording, was also recorded sequentially. Epicardial activation was taken to be at the onset of phase $O$ of the action potential. Small 'extrinsic' potentials resulting from conduction delay between intra- and extracellular electrodes and creating a small foot at the base of phase $O$ were minimised by closer positioning of the reference electrode to the recording electrode and excluded from analysis. Closely reproducible data were obtained from multiple impalements at one site and from continuously recorded control measurements from one electrode before ischaemia. Absolute measurements of transmembrane potential and initial upstroke velocity were not considered valid on account of unavoidable signal distortion caused by movement artefact and variations in microelectrode tip potential. Satisfactory recordings could be maintained over the 5-minute period of occlusion. Data were disregarded after microelectrode tip breakage. Changes in mean epicardial ST segment elevation were derived by continuous computer analysis of the recorded extracellular electrograms (Luxton et al., 1977).

\section{Procedure}

In 8 dogs, successive 5-minute occlusions of the coronary artery were achieved with a light spring releasable clip. A 30-minute period of recovery was allowed after each period of ischaemia. When ventricular fibrillation occurred, the occlusive clip was immediately removed and the heart defibrillated by DC countershock (20 watt-second). In no case was correction of acid-base balance required.

Recordings were made before and at 0.5-minute intervals after coronary occlusion of mean epicardial ST segment elevation, endocardial-epicardial con- 
duction time, and cardiac action potential duration at 95 per cent repolarisation.

The effect of variations in heart rate was studied in a further 5 dogs again with a series of 5-minute coronary artery occlusions and 30-minute recovery periods. The first occlusion was undertaken at the dogs' intrinsic heart rate and served to condition the heart to the possible deleterious effects of ischaemia and reperfusion (see Discussion). The second occlusion was undertaken at a heart rate of 100 beats/minute achieved by combined vagal slowing and atrial pacing. During the third and subsequent occlusions, vagal stimulation was continued at the same rate, but the heart rate was increased in increments of 20 beats/minute to a maximum of 200 beats/minute for the seventh and final occlusion.

\section{STATISTICS}

All results are expressed as mean \pm standard error of mean unless stated otherwise. The significance of difference was tested by Student's $t$ test, paired or unpaired as appropriate.

\section{Results}

Before coronary artery occlusion, and with a heart rate of 175 beats/min maintained by atrial pacing, the mean action potential duration was $182 \pm 9 \mathrm{~ms}$ in 8 dogs. Endocardial-epicardial conduction time was $24 \pm 1 \mathrm{~ms}$.

\section{INITIAL CORONARY ARTERY OCCLUSION}

Acute coronary artery occlusion was rapidly followed by changes in both the duration and shape of the action potential and increased endocardialepicardial conduction time.

A representative example is shown in Fig. 1. Rapid action potential shortening was associated with an increase in endocardial-epicardial conduction time within 3 minutes of ischaemia. Potentials then assumed the appearance of 'slow response' potentials (Cranefield et al., 1972), with loss of the initial rapid upstroke phase. Electrical alternans of both action potential and ST segment elevation was evident by $3 \frac{1}{2}$ minutes of ischaemia, and $2: 1 \mathrm{~N}$ conduction block was recorded intracellularly after $4 \overrightarrow{-}$ minutes of ischaemia (Fig. 1). In some occlusions $\infty$ more irregular patterns of conduction block 으 occurred.

Mean values over the period of the initial occlu- $\bar{c}$ sion in 8 dogs are shown in Fig. 2. Mean action potential duration shortened to $140 \pm 15 \mathrm{~ms}$ at $1 \vec{\theta}$ minute $(P<0.001)$ and $113 \pm 9 \mathrm{~ms}$ at 2 minutes 6 $(P<0.001)$ though transient prolongation of mean action potential duration was seen in 1 dog within 30 seconds. Loss of action potential amplitude and initial upstroke velocity was observed but not quantified (see Methods). The appearance of 'slow response' wave forms occurred earlier in animals where mean action potential duration shortening was rapid. The progressive shortening of mean

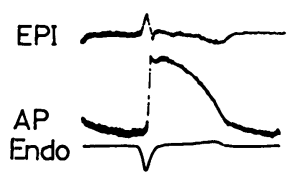

Control



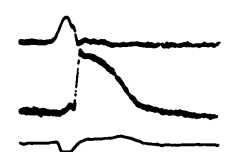

$2^{\circ}$

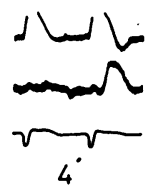

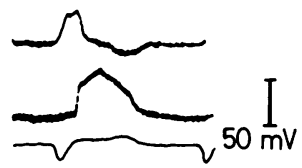

$3^{\circ}$

$100 \mathrm{~ms}$

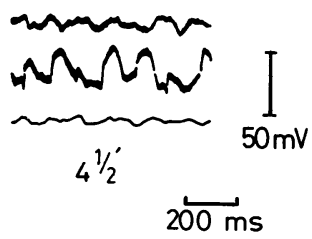

Fig. 1 Recordings of action potential $(A P)$, endocardial (ENDO), and averaged epicardial (EPI) electrograms from dog heart in situ before and $2,3,3 \frac{1}{2}$, 4 , and $4 \frac{1}{2}$ minutes after a coronary artery occlusion. Note shortening of $A P$ at 2 minutes and progressive delay in its onset with respect to the endocardial potential. Electrical alternans occurs at $3 \frac{1}{2}$ minutes and localised 2:1 conduction block at 4 minutes recorded from intracellular but not extracellular electrodes. Ventricular fibrillation occurred at $4 \frac{1}{2}$ minutes. 


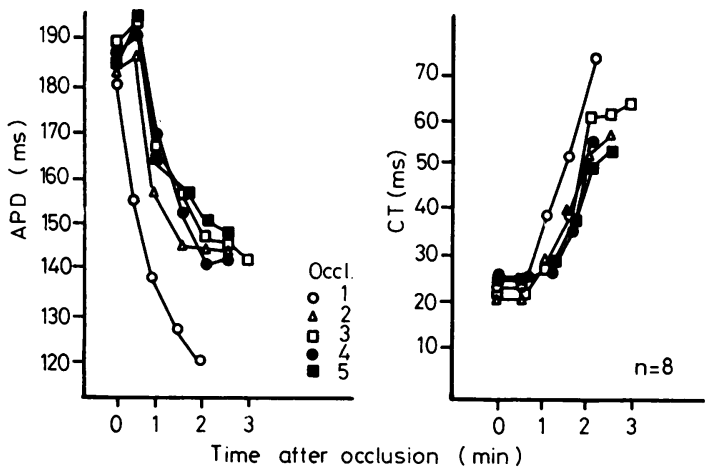

Fig. 2 Effect of successive 5-minute coronary occlusions on action potential duration and conduction delay in 8 dogs. Note the more pronounced effect of the first occlusion compared with subsequent occlusions. Mean values are shown but data discontinued on initiation of $V F$ in any dog.

action potential duration was associated in every case with prolongation of endocardial-epicardial conduction time mean values, being $38 \pm 5 \mathrm{~ms}$ at 1 minute and $71 \pm 17 \mathrm{~ms}$ at 2 minutes $(P<0.05)$. These data are illustrated in Fig. 2 and listed in Table 1.

Interpretation of epicardial ST segment change was made difficult by the appearance of widened epicardial QRS complexes in 5 dogs with severe lengthening of conduction time. However, in 3 dogs, where lesser degrees of conduction time were not associated with QRS widening, mean ST increased to $3 \cdot 5,5 \cdot 3,7 \cdot 7$, and $11 \cdot 1 \mathrm{mV}$ at $1,2,3$, and 4 minutes, respectively, after coronary artery occlusion.

\section{SUCCESSIVE CORONARY ARTERY OCCLUSIONS}

After the second coronary artery occlusion, mean action potential duration shortened and endocardialepicardial conduction time lengthened but at a slower rate than after the first occlusion. Thus, mean action potential duration shortened from $185 \pm 9 \mathrm{~ms}$ to $157 \pm 12 \mathrm{~ms}$ at 1 minute, a length significantly greater than that at 1 minute after occlusion $1(P<0.005)$. Progressive prolongation of endocardial-epicardial conduction time was also more gradual than after occlusion 1 (Table 2). There was, however, no significant difference in the rate of changes in mean action potential duration and conduction time between occlusions $2,3,4$, and 5 (Fig. 2 and Table 2). Control mean action potential duration showed slight successive prolongation before successive occlusions despite constant heart rate (Fig. 2).

The slower development of change in mean action potential duration and endocardial-epicardial conduction time was also associated with slower development of ST segment elevation in second and subsequent occlusions in those occlusions not developing gross intraventricular conduction abnor-

Table 1 Effect of initial coronary occlusion on action potential duration and endo-epicardial conduction time

\begin{tabular}{|c|c|c|c|c|c|c|}
\hline \multirow[t]{2}{*}{ Case no. } & \multirow{2}{*}{$\frac{\text { Preocclusion }}{0}$} & \multicolumn{5}{|c|}{ Minutes after coronary occlusion } \\
\hline & & 1 & 2 & 3 & 4 & 5 \\
\hline \multicolumn{7}{|c|}{ Action potential duration } \\
\hline 1 & 220 & 220 & 150 & 140 & 100 & 100 \\
\hline 2 & 150 & 130 & 105 & 150 & 160 & 120 \\
\hline 3 & 190 & 110 & 100 & $\star$ & & \\
\hline 4 & 180 & 140 & 150 & 150 & 170 & 155 \\
\hline 5 & 190 & 130 & $80 / 140 \dagger$ & $\star$ & & \\
\hline 6 & 190 & 150 & 120 & $115 / 160 t$ & $90 / 160 t$ & $\star$ \\
\hline 7 & 155 & 98 & $85 / 120 \dagger$ & & & \\
\hline 8 & 185 & 175 & 120 & $120 / 140 \dagger$ & $\star$ & \\
\hline Mean \pm SEM & $182 \pm 8$ & $140 \pm 13$ & $113 \pm 9$ & & & \\
\hline \multicolumn{7}{|c|}{ Endocardial-epicardial conduction time } \\
\hline 1 & 28 & 32 & 48 & 90 & 80 & 25 \\
\hline 2 & 20 & 28 & 42 & 60 & 110 & 80 \\
\hline 3 & 27 & 27 & 62 & $\star$ & & \\
\hline 4 & 20 & 20 & 24 & 30 & 32 & 33 \\
\hline 5 & 24 & 44 & 100 & $\star$ & & \\
\hline 6 & 20 & 28 & 160 & 165 & 168 & $\star$ \\
\hline 7 & 28 & 58 & 75 & $\star$ & & \\
\hline 8 & 26 & 28 & 52 & 68 & $\star$ & \\
\hline Mean \pm SEM & $24 \pm 1$ & $38 \pm 5$ & $71 \pm 17$ & & & \\
\hline
\end{tabular}

*Onset of ventricular fibrillation.

tIn these cases, alternans of the action potential occurred. The upper and lower limits are shown. 
Table 2 Effect of successive coronary occlusions on action potential duration, endocardial-epicardial conduction time, and incidence of ventricular fibrillation

\begin{tabular}{|c|c|c|c|c|c|c|}
\hline \multirow[t]{2}{*}{ Occlusion no. } & \multirow{2}{*}{$\frac{\text { Preocclusion }}{0}$} & \multicolumn{5}{|c|}{ Minutes after coronary occlusion } \\
\hline & & 1 & 2 & 3 & 4 & 5 \\
\hline $\begin{array}{l}\text { Action potentia } \\
1 \\
2 \\
3 \\
4 \\
5\end{array}$ & $\begin{array}{l}\text { uration } \\
182 \pm 8 \\
185 \pm 8 \\
191 \pm 8 \\
190 \pm 9 \\
188 \pm 12\end{array}$ & $\begin{array}{l}140 \pm 13 \\
157 \pm 12 \\
170 \pm 8 \\
169 \pm 8 \\
177 \pm 13\end{array}$ & $\begin{array}{l}113 \pm 9 \\
143 \pm 9 \\
147 \pm 6 \\
140 \pm 5 \\
153 \pm 9\end{array}$ & $136 \pm 7$ & & \\
\hline $\begin{array}{l}\text { Endocardial-ep } \\
1 \\
2 \\
3 \\
4 \\
5\end{array}$ & $\begin{array}{l}\text { rdial conductio } \\
24 \pm 1 \\
24 \pm 2 \\
25 \pm 1 \\
25 \pm 1 \\
24 \pm 2\end{array}$ & $\begin{array}{l}38 \pm 5 \\
29 \pm 4 \\
27 \pm 1 \\
28 \pm 1 \\
28 \pm 3\end{array}$ & $\begin{array}{l}71 \pm 17 \\
51 \pm 6 \\
49 \pm 5 \\
51 \pm 6 \\
44 \pm 9\end{array}$ & $68 \pm 5$ & & \\
\hline $\begin{array}{l}\text { No. of animals } \\
1 \\
2 \\
3 \\
4 \\
5\end{array}$ & $\begin{array}{l}\text { th ventricular } \\
- \\
- \\
- \\
-\end{array}$ & $\begin{array}{l}\text { ion } \\
= \\
=\end{array}$ & $\begin{array}{l}z^{1} \\
-\end{array}$ & $\begin{array}{r}3 \\
-\quad \\
1 \\
1\end{array}$ & $\begin{array}{l}4 \\
2 \\
3 \\
2 \\
3\end{array}$ & $\begin{array}{l}5 \\
3 \\
4 \\
4 \\
4\end{array}$ \\
\hline
\end{tabular}

Mean \pm standard error of mean values from 8 dogs are shown.

mality. A representative example of change in mean ST segment elevation is produced in Fig. 3.

\section{ONSET OF VENTRICULAR FIBRILLATION}

Ventricular fibrillation followed in 5 of 8 dogs at a mean time of 3 minutes 23 seconds after the first occlusion and 4 minutes 44 seconds after the second occlusion. It developed in only 4 dogs after $3 \mathrm{rd}$ and

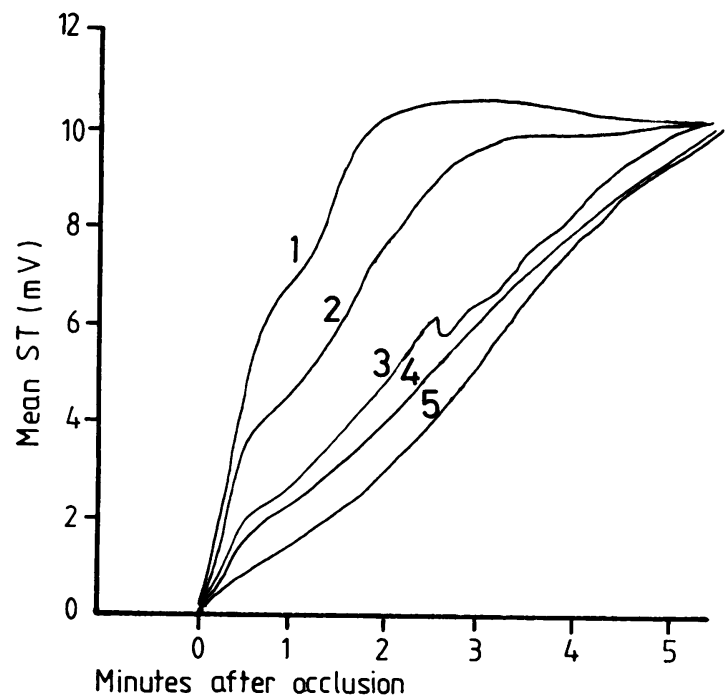

Fig. 3 Effect of successive high coronary arterial occlusions on mean epicardial ST segment elevation in one dog. Data processed by an ST segment computer. 4th occlusions (mean times of onset 4 minutes 6 seconds, 3 minutes 33 seconds). In each case, this arrhythmia was preceded by the development of action potential alternans-both duration and amplitude. These changes were accompanied by epicardial and by endocardial ST segment alternans (Fig. 1), and by varying degrees of conduction blocks with either $2: 1,3: 1$, or more irregular patterns of endocardial-epicardial conduction block.

The temporal relations between changes in mean action potential duration, endocardial-epicardial conduction time, and electrical alternans or conduction block before development of ventricular fibrillation are shown in Fig. 4. Data are taken from 20 occlusions in 5 dogs all resulting in ventricular fibrillation. Ventricular fibrillation was never seen without shortening of mean action potential duration and lengthening of endocardial-epicardial conduction time. Electrical alternans was seen in $19 \mathrm{~N}$ instances (95\%) and conduction block in $13(65 \%)$.

By contrast during occlusions not resulting in ventricular fibrillation, electrical alternans was observed in 72 per cent and conduction block in 33 per cent of instances during the 5-minute occlusion period. The mean time of onset of alternans was 3 minutes 12 seconds and block 4 minutes 8 seconds compared with 2 minutes 24 seconds and 2 minutes 48 seconds, respectively when ventricular fibrillation developed.

EFFECT OF HEART RATE

Controlled heart rates from 100 to 200 beats/minute were achieved with combined atrial pacing and 

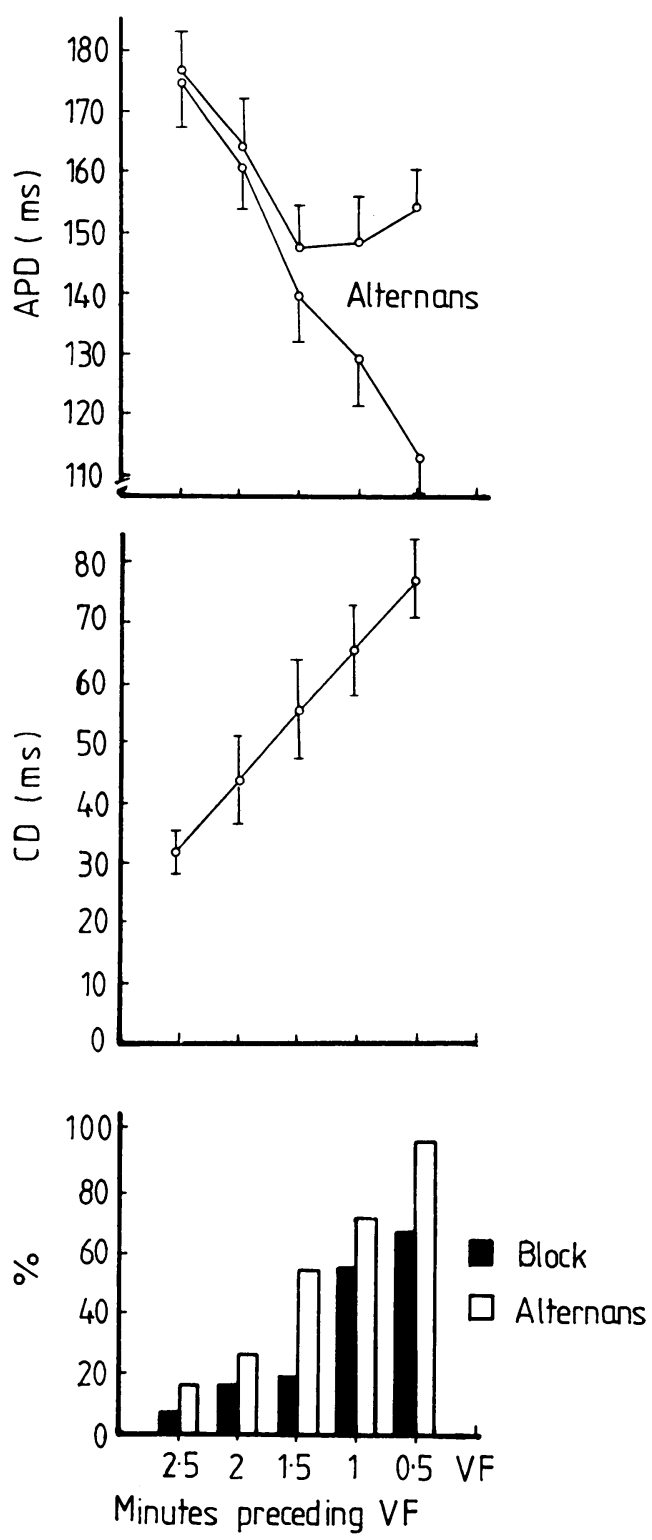

Fig. 4 Changes in action potential duration, conduction delay, and frequency of AP alternans and block before onset of ventricular fibrillation. The two values of $A P D$ refer to alternating values.

vagal stimulation, during occlusions 2 to 7 in 5 dogs. In every case control mean action potential duration was physiologically dependent on the heart rate, that is mean action potential duration before occlusion was shorter at faster heart rates. After coronary occlusion at slower heart rates, transient lengthening of the action potential duration was

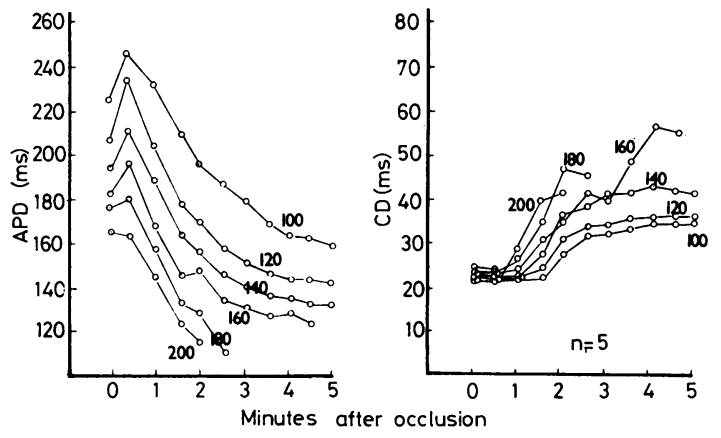

Fig. 5 Effect of increasing heart rate in second and subsequent coronary occlusions in 5 dogs on APD and $C T$. Note the initiation of VF at higher rates.

seen in every case. This was maximal at a heart rate of 100 beats/min where, after 30 seconds, mean action potential duration increased from $224 \pm 35$ to $245 \pm 41 \mathrm{~ms}$. After 1 minute, mean action potential duration shortened and endocardial-epicardial conduction time lengthened, as in the constant heart rate study, but the rate of progression became faster as the heart rate was increased with later occlusions. This was in contrast to the controlled rate study where changes tended to become milder with successive occlusions.

Mean ST segment elevation similarly showed progressively larger values with increase in heart rate. After 2 minutes of occlusion mean ST was $1 \cdot 5,2 \cdot 1,2 \cdot 6,4 \cdot 8,6 \cdot 2$, and $6 \cdot 0$ at $100,120,140,160$, 180 , and 200 beats/minute, respectively.

Ventricular fibrillation was not seen at heart rates of 100 to 140 beats/min but occurred in 1 dog at 160 beats $/ \mathrm{min}, 2$ dogs at 180 beats $/ \mathrm{min}$, and 3 dogs at 200 beats $/ \mathrm{min}$.

These data are illustrated in Fig. 5.

\section{Discussion}

These studies show quantitatively the rapid electrophysiological changes occurring at myocardial cellular level, which precede the development of early ventricular fibrillation during acute myocardial ischaemia and amplify findings briefly described in a preliminary communication from our laboratory (Russell et al., 1977). These changes are characterised by shortening of the action potential, prolongation of endocardial-epicardial conduction delay, and the appearance of potentials of 'slow response' type morphology. In addition, they are shown to be less severe during second and subsequent periods of ischaemia and at slower heart rates.

Direct recording of transmembrane action potentials in the beating heart was performed using 
floating microelectrodes. We have modified previously reported techniques (Woodbury and Brady, 1956; Prinzmetal et al., 1962; Czarnecka et al., 1973) to permit more stable recordings from ischaemic myocardium in vivo. Restriction of cardiac movement by a metal ring to protect electrode impalement was not required since the fine distal tip of the electrode was supported proximally by a wedge of thicker glass. The problem of myocardial splinting causing alterations of regional blood flow was thus avoided. Measurements of absolute membrane transmembrane potential and upstroke velocity were not performed in our experimental preparation because of tip movement artefact and intermittent incomplete cellular impalement.

The effect of anoxia and ischaemia in shortening the action potential and decreasing its amplitude is well known (Trautwein et al., 1954; McDonald and McLeod, 1973). These changes were clearly shown in the present study but occurred more rapidly than in previously reported in vitro studies of anoxic myocardium or isolated perfused pig hearts (Downar et al., 1977b) and were particularly prominent after coronary occlusions that eventually resulted in ventricular fibrillation. For example, action potential duration after 3 minutes of ischaemia was 50 to 60 per cent of control and comparable to the degree of shortening achieved after 30 minutes of anoxia in isolated ventricular muscle preparations. This action potential shortening during ischaemia is thought to result from diminished energy-dependent calcium slow-flux under conditions of reduced ATP availability of adenosine triphosphate and to reflect the abnormal energy balance within ischaemic tissue (McDonald and McLeod, 1973). At slower heart rates, and therefore presumably with milder ischaemia, transient prolongation of the action potential was often noted during the initial 30 seconds after coronary occlusion. This effect after acute ischaemia could be related to the greatly prolonged potentials shown in chronically ischaemic conduction tissue (Friedman et al., 1975).

The induction of 'slow response' type morphology potentials within 3 minutes of ischaemia presumably results from inactivation of rapid inward sodium current after rapid loss of membrane potential (Weidmann, 1955). Membrane depolarisation during ischaemia has been described in the dog (Samson and Scher, 1960; Prinzmetal et al., 1962) and in the pig heart (Kléber et al., 1978) and related to TQ segment depression of the extracellular electrogram. A loss of action potential amplitude was observed in our series though not quantified, which is consistent with these observations. This contrasts with findings during in vitro studies of anoxic myocardium that have demonstrated gross shortening of action poten- tial but with maintenance of transmembrane resting $c$. potential. Slowing of intramyocardial conduction $\underset{\vec{\rho}}{\vec{\rho}}$ particularly between endocardium and epicardium $\stackrel{0}{\frac{\rho}{O}}$ during ischaemia is well described (Durrer et al., $\frac{}{O}$ 1971, Cox et al., 1973) and has also been ascribed to $\frac{\bar{\sigma}}{\omega}$ the development of 'slow potentials' (Cranfield $e t \underset{\mathbb{\sigma}}{\overparen{D}}$ al., 1972). In the present study, action potentials $\cong$ with a morphology similar to these slow response कs potentials were associated with pronounced con- $\overrightarrow{0}$ duction delays of 50 to $150 \mathrm{~ms}$.

Alternans both of amplitude and of duration of $\vec{\omega}$ the action potential was observed between 2 and 5 minutes of ischaemia and was most obvious during

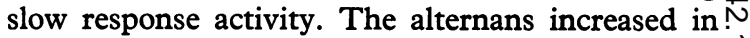
magnitude with time and in several dogs developed $\vec{\infty}$ into intermittent conduction block with either $a^{\infty}$ $2: 1$ or more irregular patterns. These changes were $\stackrel{\circ}{工}$ reflected in the surface electrocardiogram as $\mathrm{ST}_{\vec{C}}$ segment alternans. Similar alternating phenomena have been described in ischaemia (Downar et al., 1977b) and in association with arrhythmias (El- $\bullet$ Sherif et al., 1977). In our series electrical alternans of the action potential preceded ventricular fibrillation in 95 per cent of cases and epicardial conduction block preceded fibrillation in 65 per cent. Moreover, both alternans and conduction block occurred earlier and more frequently in occlusions resulting $\mathscr{\complement}$ in fibrillation. Electrical alternans could arise either $\overrightarrow{\vec{O}}$ by a true cellular potential alternans (Kleinfeld and 3 Stein, 1968) or by means of electrotonic interaction $₹$ between adjacent areas of intermittent conduction? block (Hellerstein and Liebow, 1950). An increase in diastolic excitability threshold, as may follow an increase in extracellular potassium, could account for the conduction blocks observed in this study 3 . (Elharrar et al., 1977). Alternatively, a myocardialo depressant factor has been isolated from ischaemic venous effluent blood with pronounced depressanto effects on excitability (Downar et al., 1977a). Electrical uncoupling of hypoxic or anoxic cardiac cellso has been shown in vitro and may contribute to inhomogeneity of impaired ventricular conduction ${ }^{\circ}$ during ischaemia (Wojtczak, 1976). Though the N association between the electrical phenomena and స్ల్ fibrillation is most striking it need not necessarilyo imply a cause and effect relation.

The presence of 'slow response' activity and $\frac{0}{\Phi}$ distinct endocardial-epicardial conduction delays $\stackrel{\oplus}{-}$ however would provide the exact setting for initia- 0 tion of arrhythmias by re-entrant excitation. In addition, local heterogeneity of unidirectional con- $\stackrel{\mathbb{Q}}{\circ}$ duction block may result from regional variations in $\mathbb{Q}$ diastolic excitability threshold. It is possible, there- $\frac{\Omega}{\sigma}$ fore, that quite local discrete regional asynchrony of excitability occurring simultaneously in manyo regions of the ischaemic ventricle may be of impor- 
tance in the initiation of ventricular fibrillation. Multifocal re-entrant excitation would then be possible in areas of myocardium of a few millimetres diameter. Abnormal automaticity which is an alternative possible mechanism has been shown in 'slow response' ventricular muscle fibres as well as in conducting tissue (Imanishi and Surawicz, 1974). No such activity however was recorded during any cellular impalement preceding ventricular fibrillation arguing against its role in early ventricular arrhythmogenesis.

Observations during later occlusions at varying heart rates confirmed the findings of other workers (Han, 1969; Kent et al., 1973) that the vulnerability of the heart to ventricular ischaemia is enhanced with increasing heart rate. In the present study, ventricular fibrillation did not occur at rates below 140 beats $/ \mathrm{min}$. At higher heart rates the relation between earlier onset of fibrillation and more rapid changes in action potential and conduction during ischaemia is consistent with re-entrant excitation and strongly supports a re-entrant mechanism for the early phase of cardiac arrhythmias after acute myocardial ischaemia.

Another result of these studies is one of practical importance for those investigating experimental myocardial infarction in that electrophysiological measurements have been shown to be different during the first compared with subsequent occlusions. Thus, in the 5 dogs which developed ventricular fibrillation, the mean time of onset of this arrhythmia occurred 45 or more seconds earlier during the first occlusion. Similarly, after later occlusions, a slower rate of shortening of action potential and prolongation of conduction delay, together with less ST segment elevation, was observed despite comparable heart rates. These findings suggest enhanced vulnerability of the myocardium to arrhythmias during initial coronary artery occlusions and are consistent with an altered ischaemic response in the relevant area of myocardium during successive periods of occlusion. This phenomenon is compatible with the finding of diminished contractility in myocardium reperfused after transient ischaemia (5 to 10 minutes coronary occlusion) (Vatner et al., 1975; Smith et al., 1978). If ischaemia damages the contractile apparatus, a situation of reduced oxygen demand, and hence less oxygen debt, could then be created during a second or subsequent occlusion. Milder changes during a second or subsequent occlusion may reflect some adaptive mechanism controlling coronary blood flow and related to greater vasodilator activity consequent upon release of vasoactive adenine nucleotides (Berne and Rubio, 1969). Alternatively, depletion of noradrenaline during the first occlusion could alter the metabolic and electrophysiological responses to successive occlusions. This lack of reproducibility of electrophysiological data between the initial and subsequent periods of ischaemia indicates that studies by other workers employing similar experimental models of repetitive coronary occlusion should be critically reappraised. Comparative studies of metabolic or pharmacological intervention during ischaemia may have little validity if not performed after an initial sham occlusion.

\section{References}

Berne, R. M., and Rubio, R. (1969). Acute coronary occlusion: early changes that induce coronary dilatation and development of collateral circulation. American fournal of Cardiology, 24, 776-781.

Cox, J. L., Daniel, T. M., and Boineau, J. P. (1973). The electrophysiologic time course of acute myocardial ischaemia and the effects of early coronary artery reperfusion. Circulation, 48, 971-983.

Cranefield, P. F., Wit, A. L., and Hoffman, B. F. (1972). Conduction of cardiac impulses. III. Characteristics of very slow conduction. Fournal of General Physiology, 59, 227-246.

Czarnecka, M., Lewartowski, B., and Prokopczuk, A. (1973). Intracellular recording from the in situ working dog heart in physiological conditions and during acute ischaemia and fibrillation. Acta Physiologica Polonica, 24, 331-337.

Downar, E., Janse, M. J., and Durrer, D. (1977a). Effect of "ischemic" blood on transmembrane potentials of normal porcine ventricular myocardium. Circulation, 55, 455-462.

Downar, E., Janse, M. F., and Durrer, D. (1977b). The effect of acute coronary occlusion on subepicardial transmembrane potentials in the intact porcine heart. Circulation, 56, 217224.

Durrer, D., Van Dam, R. T., Freud, G. E., and Janse, M. J. (1971). Re-entry and ventricular arrhythmias in local ischemia and infarction of the intact dog heart. Proceedings of the Koninklijke Nederlandse Akademie van Wetenschappen. Series C. Biological and Medical Sciences, 74, 321-334.

Elharrar, V., Foster, P. R., Jirak, T. C., Gamm, W. E., and Zipes, D. (1977). Alterations in canine myocardial excitability during ischemia. Circulation Research, 40, 98-105.

El-Sherif, N., Scherlag, B., Lazzara, R., and Hope, R. R. (1977). Re-entrant ventricular arrhythmias in the late myocardial infarction period. I. Conduction characteristics in the infarction zone. Circulation, 55, 686-702.

Friedman, P. C., Fenoglio, J. J., jun, and Wit, A. L. (1975). Time course for reversal of electrophysiological and ultrastructural abnormalities in subendocardial Purkinje fibres surviving extensive myocardial infarction in dogs. Circulation Research, 36, 127-144.

Han, J. (1969). Mechanisms of ventricular arrhythmias associated with myocardial infarction. American fournal of Cardiology, 24, 800-813.

Harris, A. S. (1950). Delayed development of ventricular ectopic rhythms following experimental coronary occlusion. Circulation, 1, 1318-1328.

Hellerstein, H. K., and Liebow, I. M. (1950). Electrical alternation in experimental coronary artery occlusion. American fournal of Physiology, 160, 366-374.

Imanishi, S., and Surawicz, B. (1974). Lidocaine resistant automaticity in depolarized guinea-pig ventricular myocardium (abstract). Circulation, 49 and 50, Suppl. III, 145. 
Kardesch, M., Hogancamp, C. E., and Bing, R. J. (1958). The effect of complete ischemia on the intracellular electrical activity of the whole mammalian heart. Circulation Research, 6, 715-720.

Kent, K. M., Smith, E. R., Redwood, D. R., and Epstein, S. E. (1973). Electrical stability of acutely ischemic myocardium: influences of heart rate and vagal stimulation. Circulation, 42, 291-298.

Kléber, A. G., Janse, M. J., van Capelle, F. J. L., and Durrer, D. (1978). Mechanism and time course of S-T and T-Q segment changes during acute regional myocardial ischemia in the pig heart determined by extracellular and intracellular recordings. Circulation Research, 42, 603-613.

Kleinfeld, M., and Stein, E. (1968). Electrical alternans of components of action potential. American Heart fournal, 75, 528-530.

Luxton, M. R., Russell, D. C., Murray, A., Williamson, D., Neilson, J. M. M., and Oliver, M. F. (1977). Praecordial ST-segment elevation. New technique for continuous recording and analysis. British Heart fournal, 39, 493-501.

McDonald, T. F., and McLeod, D. P. (1973). Metabolism and the electrical activity of anoxic ventricular muscle. Fournal of Physiology, 229, 559-582.

Oliver, M. F. (1976). Significance of ventricular arrhythmias during myocardial ischemia. Circulation, 53 and 54, Suppl. I, 155-157.

Prinzmetal, M., Toyoshima, H., Ekmekci, A., and Nagaya, T. (1962). Angina pectoris VI. Nature of ST-segment elevation and other ECG changes in acute severe ischaemia. Clinical Science, 23, 489-514.

Russell, D. C., and Oliver, M. F. (1978). Ventricular refractoriness during acute myocardial ischaemia and its relationship to ventricular fibrillation. Cardiovascular Research, 12, 221-227.

Russell, D. C., Oliver, M. F., and Wojtczak, J. (1977). Combined electrophysiological technique for assessment of the cellular basis of early ventricular arrhythmias. Lancet, 2, 686-688.

Samson, W. E., and Scher, A. M. (1960). Mechanism of ST- segment alteration during acute myocardial injury. Circulation Research, 8, 780-787.

Scherlag, B. J., El-Sherif, N., and Hope, R. (1974). Characterisation and localisation of ventricular arrhythmias resulting from myocardial ischemia and infarction. Circulation Research, 35, 372-383.

Smith, H. J., Kent, K. M., and Epstein, S. E. (1978). Contractile damage from reperfusion after transient ischemia in the dog. Fournal of Thoracic and Cardiovascular Surgery, 75, 452-457.

Trautwein, W., Gottstein, V., and Dudel, J. (1954). Der Aktionstrom der Myokardfaser im Sauerstroffmangel. Pflüger's Archiv für die Gesamte Physiologie des Menschen und der Tiere, 260, 40-60.

Vatner, S. R., Heyndrickx, E. R., Millard, R. W., McRitchie, R. I., Bergeson, G. A., Manders, W. T., and Maroko, P. R. (1975). Effects of coronary reperfusion on myocardial is damage and regional function in conscious dogs (abstract). Clinical Research, 23, 383A.

Weidmann, S. (1955). The effect of the cardiac membrane $\infty$ potential on the rapid availability of the sodium carrying 음 system. Fournal of Physiology, 127, 213-224.

Wit, A. C., Rosen, M. R., and Hoffman, B. F. (1974). II. $\vec{c}$ Relationship and pharmacology of cardiac arrhythmias. II. Relationship of normal and abnormal electrical activity of cardiac fibers to the genesis of arrhythmias. B: Re-entry. Section I. American Heart fournal. 88, 664-670.

Woodbury, J. W., and Brady, A. J. (1956). Intracellular recording from moving tissues with a flexibly mounted ultramicroelectrode. Science, 123, 100-101.

Wojtczak, J. (1976). Electrical uncoupling of heart muscle cells in hypoxic, glucose-iree tyrode (abstract). Experientia, 32, 764 .

Requests for reprints to Professor M. F. Oliver, Department of Cardiology, The Royal Infirmary, Edinburgh EH3 9YW. 